\title{
A study of bereavement care after a sudden and unexpected death
}

\author{
Ann Dent, Louise Condon, Peter Blair, Peter Fleming
}

\begin{abstract}
Bereaved parents' perceptions of care after the sudden, unexpected death of their child (from 1 week to 12 years), and the care that was or could be offered by statutory and voluntary agencies, was assessed in 11 health districts in seven regions of England and Wales. In these 11 districts, 185 families were identified who met the criteria of the study. Permission to contact these families was given by only 72 general practitioners. Of these, 42 families responded (58\%). Sudden infant death syndrome accounted for $43 \%$ of the deaths.
\end{abstract}

The results from postal questionnaires sent to both parents showed that hospital care was perceived as good on the whole, although parents would like more choices. Most parents felt that community care was inadequate, leaving many feeling isolated. In contrast, questionnaires from health visitors and general practitioners in the same health districts showed that they believed that they were the most appropriate professionals to give follow up care, but as there were few policies to guide them and little training provided, felt unable to offer support. (Arch Dis Child 1996;74:522-526)

Keywords: bereavement care, sudden death.

While there is an expanding literature on the emotional responses of families to the death of an infant or child, ${ }^{1-6}$ no studies have concentrated on how bereaved parents view the care they have received, how care is coordinated between the voluntary and statutory agencies, or how equipped professionals and volunteers are to meet the needs of bereaved families. Finlay and Dallimore suggested in their study of 150 bereaved parents, all members of the voluntary agency, Compassionate Friends, that there was a serious need to revise the in-service training of the police and the health professionals, particularly in their approach to informing of the death, and that parents should be allowed more time with their dead child with fewer restrictions on what they could do with the body. ${ }^{7}$

This report gives the results of a two year qualitative, retrospective study carried out in 11 health districts of England and Wales, to establish what parents thought of the care they had received both from the statutory and voluntary agencies after their child died suddenly and unexpectedly from accident or illness. It also shows what professionals and voluntary agencies in the same health districts as the bereaved parents, can offer in the way of support.

\section{Methods}

AREAS INCLUDED IN THE STUDY

The study was carried out in England and Wales. Of the 14 health regions, seven were selected, namely: Northern, Trent, East Anglia, NE Thames, Wessex, Mersey and Wales, taking into consideration geographic, socioeconomic, urban, rural, and ethnic factors. Two health districts within each of these regions were chosen for study. Ethical approval was sought from 15 health districts (one being for the pilot study). In four regions it was possible to utilise only one health district as two ethical committees did not consent to the study, and in another two health districts, although ethical approval had been given, local paediatricians did not give the information required to carry out the study. In the latter two health districts, it was possible to obtain information from health professionals and voluntary agencies but not from bereaved parents. All ethical committees, except one, wished us to contact the families' general practitioner for permission to contact the bereaved parents.

A pilot study was conducted in one health district. Because there were minimal changes to the questionnaires, and no modification of the protocol, the results from the pilot study are therefore included in the overall results. As a consequence, the full study was carried out in 11 health districts, from seven different health regions.

\section{INCLUSION CRITERIA}

The study included all families whose children from 1 week to 12 years had died suddenly and unexpectedly from accident or illness from the beginning of May 1991 to the end of May 1993.

EXCLUSION CRITERIA

Families whose children had died of a possible non-accidental injury, who had been murdered, had died as a result of suicide, or a chronic life threatening disease, or who had moved abroad since the death of their child, were not included in the study.

DESIGN OF PARENTAL QUESTIONNAIRE

Postal questionnaires were chosen to obtain the required information from bereaved parents. This method was adopted because of the wide distribution of bereaved families throughout the UK and the limited length of time to 
complete the study. The questionnaires were designed to gain information from both fathers and mothers on their perceptions of, and satisfaction with, the care they had received from the emergency services, hospital staff, the coroners' officers, the clergy, funeral directors, Department of Social Security staff, the media, voluntary agencies, and members of the primary health care teams. Advice was sought from bereaved parents in both the design of the questionnaire and how the questions were asked.

To maintain confidentiality, respondents could only be identified by region, district, and questionnaire type. Any names of people or institutions or dates given by the respondents were removed from the completed questionnaires.

QUESTIONNAIRES TO HEALTH PROFESSIONALS AND VOLUNTARY AGENCIES

The option of sending questionnaires to the general practitioners and health visitors who had actually been involved with bereaved families was considered. However, it was rejected because of lack of available time to follow up those who had been involved in this way. It was felt that a random sample would be less threatening and would give a clearer picture of what could or had been offered in each health district.

For each chosen health district, questionnaires were designed to send to 20 health visitors and 20 general practitioners randomly selected, all hospital accident and emergency departments, hospital chaplains, emergency services, and national voluntary agencies (CRUSE, Foundation for the Study of Infant Deaths, SANDS, Compassionate Friends) in that district. In each of the chosen health districts, a local paediatrician was asked to assist the project by giving local information and support to the study. Only one declined.

\section{Results}

SAMPLE SIZE

Although 185 eligible families were identified, only 72 were included in the study. Almost two thirds of the families could not be approached

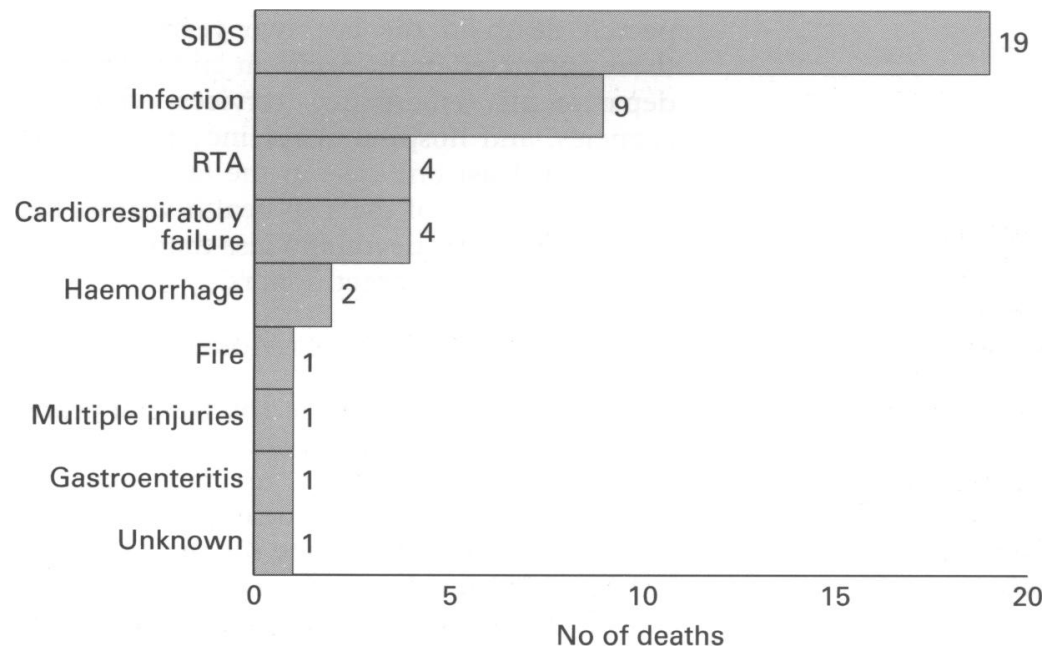

Figure 1 Cause of death in 42 children; SIDS = sudden infant death syndrome, RTA = road traffic accident. because the general practitioner refused permission, could not locate records, did not reply to our request, or could not be traced. Furthermore, in two health districts, identified families could not be contacted due to lack of information from local paediatricians. Of the 72 families contacted, 42 returned questionnaires, giving a response rate of $58 \%$.

Figure 1 shows the cause of death of the children whose parents were contacted.

The age of death of the children ranged from 2 weeks to 10 years, the majority of the children being less than 1 year old $(61 \%)$. Exactly half the deaths occurred in the home, most of the other deaths taking place in intensive care units. In 25 cases, both parents replied, and in 17 cases just one of the parents (15 mothers and two fathers).

\section{ANALYSIS OF PARENTAL RESPONSES}

Emergency services

Most parents were satisfied with the care given by the police, ambulance, and fire brigade. Many praised the efficiency of the ambulance staff in dealing sensitively with the situation, although a third of the parents were not able to accompany their child in the ambulance. A number of parents $(28 \%)$ felt that the police could have been more sympathetic and less accusing.

\section{Hospital service}

Care of their child while in hospital was perceived by $92 \%$ of parents as being good. Care by hospital doctors and nurses was considered good by $77 \%$ of parents. All parents had been told sensitively about their child's death. 'We were told very, very sensitively by the doctor in charge, told with some emotion and sadness which helped us enormously'.

Most hospitals had facilities available to help the bereaved parents, although few intensive care units provided a play area for the siblings or offered transport home if required.

Over a quarter of parents were not given information as to what was happening to their children while being treated before they died, and a third would have appreciated someone to sit with them while waiting before the death. Most couples were given the opportunity of holding their child after death. Only a quarter of the parents were aware that they could wash the body, bring siblings to see the dead child, and accompany the body to the mortuary.

Less than half the parents were offered a photograph and only a very small number were offered hand and foot prints, or a lock of hair. In retrospect, most parents would have liked these mementoes.

Less than half of the parents were offered a help-line telephone number or a contact number for a support group. Many would have valued leaflets on bereavement issues, especially on how to help bereaved siblings, explanation of postmortem examinations, and how to register the death.

Coroner's officer

Questions were asked regarding the parent identifying the child's body, taking away clothing and bedding, and collecting information 
about the circumstances of the death. Most parents felt that this had been carried out in a sensitive manner by the coroner.

\section{Media contact}

Over half of the deaths (55\%) were reported either in newspapers, on television, or the radio. Many parents were deeply upset by the insensitivity of the reporters and the inaccuracy of the reports. 'Totally horrifying! It was one of the most distressing parts of the tragedy'.

\section{Dealing with governmental departments}

In half the cases the parents were not told about informing the Department of Social Security about the death of their child. Most were satisfied with the attitude of the departmental staff, although a small number felt angry with their lack of sensitivity.

\section{Postmortem examinations}

Most examinations (74\%) were conducted within two days of the death. None took longer than six days. Most parents understood the findings and were able to ask questions, but nearly half did not understand the answers to their questions. Those whose infants had died from sudden infant death were distressed that there was no medical explanation. Such comments as 'There weren't any answers to his death. There was nothing wrong with him' were common for responses. These parents were also unaware that organ donation was not possible and could not understand why they had not been asked.

\section{Funeral}

All parents were satisfied with the service offered by funeral directors and the way in which the service was conducted by the clergy.

\section{Support for bereaved parents}

More than half the parents were not offered follow up care at the hospital to talk of the death with a paediatrician. Of those that were, $88 \%$ thought the meeting was helpful. Only $13 \%$ of families received formal support from their general practitioners and $12 \%$ from

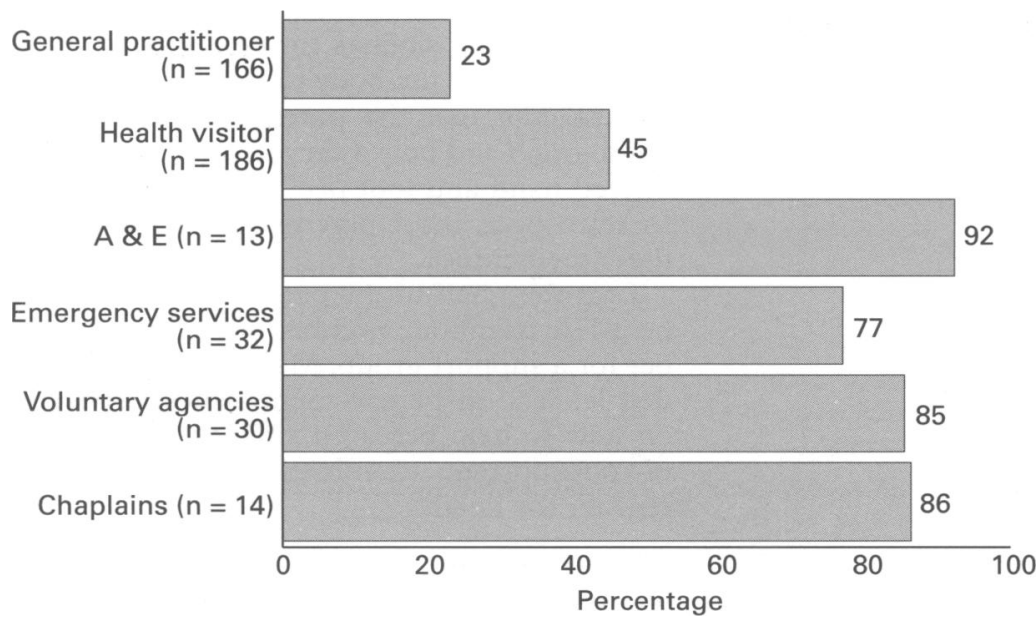

Figure 2 Involvement with sudden unexpected deaths in children 1 week to 12 years; $A \mathcal{E} E=$ accident and emergency department. health visitors. Those who had been helped by their general practitioner and/or health visitor, commented how helpful this had been. Only $36 \%$ had made contact with a local support group. A further $18 \%$ said they would have liked to. Around $90 \%$ felt that their partner sometimes or quite often provided them with emotional support, but $55 \%$ said they had experienced a serious strain in their relationship with their partner. Two thirds of parents turned to other bereaved parents. Less than $10 \%$ felt there was no-one to give support.

Other children in the family

Of the 42 families involved in the study, 33 had other children, 68 in total (the number ranged from $0-5$, the median being 2). The ages ranged from 1 month to 15 years. Of the 50 children aged 2 or over, three quarters of families said they had noticed behavioural changes, the most common being withdrawal (39\%). Other families also listed stealing, sleeping problems, crying over little things, pretending to be a baby, wanting lots of attention, and putting on excessive weight. Only $27 \%$ of these families had been given advice from health professionals about the needs of grieving siblings and only two of the children were receiving professional support (one from a bereavement counsellor the other from a social worker). Two thirds of the parents thought the health professionals could have been more helpful in dealing with bereaved siblings. Many parents advocated the need for professionals to conduct home visits and to make regular contact.

ANALYSIS OF RESPONSES FROM THE HEALTH PROFESSIONALS AND VOLUNTARY AGENCIES

Of the 598 institutions or individuals contacted, the overall response rate was $74 \%$. Of the 36 emergency services contacted $89 \%$ responded, 13 of the 15 accident and emergency departments responded and 14 of the 15 hospital chaplains. Of the 240 general practitioners contacted, $69 \%$ responded as did $78 \%$ of the 240 health visitors. The lowest response was from the voluntary agencies, $63 \%$ of the 48 voluntary agencies responded.

Figure 2 shows the involvement of each group of professionals with a sudden unexpected death in the last two years. Most of those contacted in the accident and emergency departments, emergency services, voluntary agencies, and hospital chaplaincy had experience of at least one case in the last two years. Less than a half of the 186 health visitors had dealt with such a death and less than a quarter of the 166 general practitioners.

ANALYSIS OF GENERAL PRACTITIONER QUESTIONNAIRES

Although virtually all of the 166 general practitioners who responded believe that families should be offered follow up care after the death, few were aware of formal policies (only $20 \%$ were aware of a policy for the death of a baby and $7 \%$ for the death of a child).

Only $8 \%$ had been given any specific training in how to help a family bereaved through the death of a child. Most would value training and 
more information, especially on bereaved children. Many general practitioners would like leaflets to give to parents on bereaved children, understanding bereavement, and self help groups. Nearly all (96\%) believed that they and their health visitors should be involved in follow up care. Over half $(59 \%)$ felt that the voluntary agencies met unfulfilled needs of parents, and could give up to date information and resources.

ANALYSIS OF HEALTH VISITORS QUESTIONNAIRES Although $58 \%$ had been involved with the death of a child or infant in the last two years, few had policies to guide them, especially after the death of a child (only $35 \%$ of health visitors were aware of a policy for the death of a baby and $16 \%$ for the death of a child). All health visitors $(n=186)$ believed that families should be offered follow up care and that they have an active role in doing so. Three quarters had had no specific training, and all thought it would be helpful. Many expressed a wish to have more leaflets, especially on bereaved children and understanding bereavement.

ANALYSIS OF QUESTIONNAIRES FROM ACCIDENT AND EMERGENCY STAFF

More than two thirds $(n=13)$ had policies for caring for a family when a baby dies, and just under a half for the death of an older child. Over half had been given training and more than two thirds would appreciate more. What they offered parents matched up with what the parents said, in terms of what facilities, services, and choices were available.

\section{EMERGENCY SERVICES}

Responses came from 12 police stations, nine ambulance services, and 11 fire brigades. Again it was found that few policies existed for the death of a child or infant. Only a third of the police stations had a policy for the sudden death of a baby and a quarter for that of a child. Only $11 \%$ of ambulance services had a policy for the death of a baby, none for children, and no fire services had a policy for either a baby or child. Few had been given specific training, which most would find helpful.

HOSPITAL CHAPLAINS

Of the 14 hospital chaplains who returned questionnaires, all had had contact with families whose infant or child had died. Many would welcome information rather than training on specific areas. These include children in crisis, post-traumatic stress syndrome, and crisis counselling.

\section{VOLUNTARY AGENCIES}

Of the $30(62 \%)$ voluntary agencies that responded, $50 \%$ offered individual counselling to bereaved parents, $87 \%$ provided befriending services, and $73 \%$ ran support groups for parents. However, only $27 \%$ had support groups for grandparents and only $13 \%$ had support groups for siblings. Two thirds provided training for their volunteers, but only a quarter gave specific training on how to help parents whose infant or child had died suddenly. Most ( $82 \%)$ thought this would be useful. Many would appreciate more information especially on coordination with health professionals. Many had referrals from health visitors and worked alongside them. All would like leaflets to give to parents on grieving children and grieving parents.

\section{Discussion}

This study relied heavily on permission being granted from ethical committees in the first instance and general practitioners' approval in the second. The low sample size can be attributed mainly to 'professional blocking'. One ethics committee did not give approval as it was felt that 'parents might question why they were not offered certain facilities'. In another, paediatricians claimed that others were conducting similar research but on further investigation this was not the case. As several months had elapsed since the original proposal had been submitted, it was too late to enter a further proposal. In a further two districts, although ethical approval had been granted, the identified paediatrician in one was unwilling to release any information on children who had died, and in the other, general practitioners' names and addresses were withheld. As a result of these exclusions (and the inclusion of the pilot study) the study was conducted in only 11 of the 15 districts. All ethical committees except one were insistent that families' general practitioners were approached initially for permission to contact bereaved parents. Consequently, the number of families was greatly reduced. It may be that ethical committees were being inappropriately protective of families and denied the families therefore the opportunity to voice their concerns and ways in which care could be improved. Similarly the general practitioners who refused contact may have done so for many reasons not related to whether the family wished to complete the questionnaire or not. There is therefore an implication that ethics committees and medical personnel felt threatened by the study.

From the number of infant deaths identified in the study, a mean of nine children per health district (ranging from three to 17 deaths) died each year from sudden and unexpected causes of accident or illness. Although the number of children is small, the numbers of those affected by the death are not. Taken nationally, around 2000 families will be affected each year; approximately 4000 parents, a possible 8000 grandparents, and an unknown number of siblings.

The findings of Finlay and Dallimore's study ${ }^{7}$ have been partly confirmed in this present study, in that while most parents were satisfied with the emergency services as a whole, some parents felt the police could have handled the situation more sensitively. There was, however, universal praise for the health professionals in the manner in which the parents were told of the death. Further, this study agrees with Finlay and Dallimore's study in that parents want to spend more time with their dead child and would appreciate more choices, for example in accompanying their 
child to the mortuary, washing their child, and bringing siblings to see their dead brother or sister. Parents would also like more mementoes such as hand and foot prints, and locks of hair.

The parents' perceptions of behavioural changes in their surviving children is a matter for concern. Very few parents received any professional help. Most of the parents who had other siblings wanted more information and help from the health professionals.

More than 30 years ago, Cain et al commented ${ }^{8}$ ' $A$ full preventive-therapeutic approach to the dead child's siblings, integrated with assistance to the grieving parents, remains to be carefully spelled out. But recognition of the need for such efforts represents a major step towards preventing what we called elsewhere, the senseless arithmetic of adding newly warped lives to the one already tragically ended'. It would appear that little has changed.

It is apparent that all professional groups would value more training and information.

General practitioners and health visitors see themselves as the most appropriate professionals to support bereaved families and yet few are aware of specific policies to provide guidelines for bereavement support. Many feel inadequate to care for such families, especially bereaved siblings. Many health visitors feel that they are unsupported and unsupervised in bereavement care.

\section{Conclusions}

Although the number of families that could be included in this study was small in comparison to those that were identified, the evidence suggests that improvement could be made in the following areas:
(1) More choices should be available to parents in hospitals.

(2) A system of identifying bereaved families should be established in each health district to ensure that an appropriately trained paediatrician can offer support either directly or preferably through the parents' general practitioner. Home visits are seen by families as especially valuable, and in view of the relatively small number of such deaths in each district, it would be entirely appropriate for a paediatrician to offer a home visit preferably with the general practitioner and/or health visitor.

(3) More structured bereavement follow up in the community should be offered to parents by health visitors and general practitioners.

(4) More training should be available to all who are involved with a family which has suffered the sudden and unexpected death of a child.

We gratefully acknowledge funding from the Foundation for the Study of Infant Deaths and from Cot Death Research.

1 Defrain JD, Ernst L. The psychological effects of sudden infant death on surviving family members. $\mathcal{F}$ Fam Pract 1978; 6: 985-9.

2 Cornwell J, Nurcombe B, Stevens L. Family response to loss of a child by sudden infant death syndrome. Med $\mathcal{F}$ Aust 1977; i: $656-8$.

3 Friedman SB. Psychological aspects of sudden infant death in infants and children. Pediatr Clin North Am 1974; 21: 103-11.

4 Kennel JH, Slyter H, Klaus MM. The mourning response of parents to the death of a new-born infant. $N$ Engl $\mathcal{F}$ Med parents to the death

5 Lauer ME, Mulhern RK, Shell MJ, Camitta BM. Long term follow up of parental adjustment following a child's death follow up of parental adjustment following a chil
at home or hospital. Cancer 1989; 63: 988-94.

6 Mandell F, McAnulty E, Reece CM. Observations of parental response to sudden unanticipated infant death. Pediatrics 1980; 65: 221-5.

7 Finlay I, Dallimore D. Your child is dead. BMF 1991; 302: 1524-5.

8 Cain AC, Fast I, Erickson ME. Children's disturbed reactions to the death of a sibling. Am $\mathcal{F}$ Orthopsychiatry 1964; 34: 741-52. 